\title{
Прокофьева Н.В.
}

\author{
Особенности морально-нравственной \\ рефлексии современного взрослого
}

Статья посвящена анализу такого сложного и многогранного феномена, как морально-нравственная реслексия. В данной работе говорится об особой актуальности проблемы исследования морально-нравственного развития современной личности и о реальной потребности как науки, так и общества в новом психологическом осмыслении данного феномена; вкратие изложены взгляды на данную проблематику сформированные в рамках гуманистически ориентированных направлений в психологии; проводится параллель между морально-нравственной рефлексией и успешным личностным развитием; говорится о необходимости формирования нравственного сознания и ответственности за это, как личности, так и общества. В эмпирической части статьи приведены результаты первого этапа экспериментального исследования морально-нравственной рефлексии современного взрослого и намечены перспективы хода дальнейшего эксперимента.

Ключевые слова: морально-нравственное развитие, моральнонравственная рефлексия, морально-нравственная автономность, ответственность, саморефлексия, личностное развитие, самореализация.

Проблема исследования морально-нравственного развития личности приобретает особую актуальность в современном российском обществе. Старая система нравственных ценностей и идеалов оказалась отвергнутой, полностью разрушены традиции и социальные регуляторы, действовавшие в прошлом. Многие люди находятся в ситуации экзистенциального и идеологического вакуума, теряют смысл жизни, что ведет к необходимости поиска опоры внутри себя, к тому, чтобы самостоятельно направлять и регулировать свою жизнь. Возросла необходимость в личностной морально-нравственной автономности, которая предполагает самостоятельность выборов, принятия решения и совершения определенных действий на основании внутренних критериев с учетом собственных психологических особенностей.

Морально-нравственное развитие как компонент личностного развития это путь человека длиною в жизнь. Этот сложный, многогранный процесс подразумевает как психологическое созревание, так и духовное становление.

Для современных психологов это достаточно очевидно. Но рефлексии значимости процесса о необходимости нравственного развития личности еще недостаточно для ответа на вопросы о том, что приводит современного человека к тотальной неудовлетворенности, невозможности быть полноценным творцом своей жизни и создавать то качество жизни, которое вдохновляет и ведет его к полному раскрытию себя в контексте современных жизненных 
реалий. Возникает реальная потребность как науки, так и общества в новом психологическом осмыслении данной категории.

Несмотря на то, что в рамках общенациональной культуры невероятно усложнены механизмы передачи духовно-нравственных ценностей, затруднена здоровая социализация молодежи и нет социальных программ, помогающих взрослому человеку осознанию и следованию истинно своим ценностям, работ, посвященных данной проблематике, немного.

В связи с очевидно «усложненной реальностью» нового времени и скоростью, с которой изменяется современная окружающая действительность, встает необходимость исследования личностных качеств, которые помогают человеку эффективно выстраивать свою жизненную реальность, сохраняя при этом свою целостность и индивидуальность [6]. Многие современные психологи отмечают, что необходимыми элементами для этого являются стремление к личностному развитию (самореализации) и способность к моральнонравственной рефлексии. Взаимосвязь данных тенденций и обусловила наш научный интерес.

Реалии нашего сложного времени диктуют необходимость перевода морально-нравственных категорий из области идеального в реальное, осознаваемое каждым человеком поле своего развития [10]. Человек развивается нравственно поэтапно, постепенно постигая свои смыслы бытия, организуя свой кристалл жизненных ценностей и приоритетов, что и позволяет ему в полной мере нести ответственность за себя и свою жизнь. «На стадии усвоения нравственных норм через систему личностных ценностей человек, используя все механизмы порождения смыслов, приходит к «полаганию» смыслов, когда смысл постигаемого содержания раскрывается через особый экзистенциальный акт, в котором субъект своим сознательным и ответственным решением устанавливает значимость чего-либо в своей жизни» [1, с. 49].

Способность к саморефлексии (умение оценить прошлое, анализировать настоящее и планировать будущее), способность к саморегуляции и здоровому волевому поведению, ответственное отношение к миру, к себе и окружению, критическая оценка и выбор своей системы ценностей, и способность на основе этого творчески и профессионально развиваться - все эти понятия современные психологи считают ключевыми в морально-нравственном становлении здоровой личности.

На основании теоретического анализа и обзора эмпирических исследований нами был очерчен круг эмпирически измеряемых конструктов разного уровня, имеющих отношение к морально-нравственной рефлексии и феномену саморазвития человека, которые отвечают логике нашего исследования, такие как: уровень морально-нравственной рефлексии, общий уровень значимости морально-нравственных категорий, уровень нравственной воспитанности и желательных ценностных отношений к себе, миру, людям, уровень развития 
смысловой сферы (осмысленность, насыщенность жизни, удовлетворенность самореализацией, наличие смысла жизни и жизненных целей), направленность ответственности в виде внутреннего или внешнего локуса контроля, общий уровень рефлексии, стремление к самореализации. Психометрические методики, измеряющие данные конструкты, вошли в подготовленную нами тестовую батарею.

Исследуя понятие «морально-нравственная рефлексия», мы апеллируем к смысловому полю, которое существует в современном психологическом понимании данной проблематики, и опираемся на степень разработанности этой проблемы в контексте приемлемом для сегодняшнего дня, т. к. еще 20 лет назад эти категории имели совершенно другую информационную наполненность и интерпретировались совершенно иначе. Исследование вопроса морально-нравственных норм включает в себя две тенденции развития: первая - понимание человека как общественного индивида, подчиняющегося общественной морали; вторая (современный подход) - понимание человека как личности, устремленной к идеалу (самореализации, зрелости, индивидуации, целостности), а понимание морали как пути к внутреннему самосовершенствованию.

Вплоть до 60-х гг. на Западе и до середины 90-х гг. XX в. в России относительно личности исключалась свобода выбора, ответственность за морально-нравственное воспитание отдавалась обществу, а все моральные выборы человека должны были быть подчинены исключительно социальной полезности.

Впервые проблема морально-нравственного самоопределения с точки зрения свободного выбора человека возникла в рамках экзистенциальногуманистического направления, основными представителями которого являются Д. Бьюдженталь, К. Роджерс, А. Маслоу, Э. Фромм, В. Франкл, Р. Мэй. Ученные данного направления впервые заговорили о вопросах самоосуществления, акцентируя внимание на духовно-ценностной составляющей развития и реализации духовной компоненты внутреннего содержания личности.

В России рамках неклассической психологии данную проблему исследуют Б.Г. Братусь, Э.В. Галажинский, В.Е. Клочко, Д.А. Леонтьев, С.Л. Братченко. В рамках духовно-нравственной психологии - Б.С. Братусь, В.И. Слободчиков, Ф.Е. Василюк.

Сформированное в рамках гуманистически ориентированных направлений представление о природе человека как о существе свободном, ответственном, имеющем двойственную материально-духовную природу, что не отрицает также его социальности, позволяет говорить о проблематике моральнонравственного самоопределения и вопросах самореализации как о двух взаимосвязанных и взаимно инициирующих категориях, предполагающих личностное развитие. 
Таким образом, актуальность темы нашего исследования обусловлена возрастанием роли человека в определении вектора личностного развития и необходимости для этого морально-нравственной определенности и автономности.

Целью первичного этапа экспериментального исследования являлось разделение респондентов на 2 экспериментальные группы по уровню моральнонравственной рефлексии. Для этого нами были разработаны две анкеты: анкета № 1 - для изучения уровня морально-нравственной рефлексии; анкета № 2 - для изучения общего уровня значимости морально-нравственных категорий и выявление наиболее значимых морально-нравственных категорий для современного взрослого.

В начале исследования в анкетировании приняли добровольное участие 200 человек: 110 мужчин и 90 женщин в возрасте от 35 до 63 лет. Все испытуемые - русские, жители города Москвы, причисляющие себя либо к христианству (без уточнения духовного направления: православие, католицизм, протестантизм), либо не имеющие возможности четко отнести себя к какому-либо типу вероисповедания.

На первичном этапе исследования при обработке анкет 30 человек были исключены из списка респондентов, т. к. показали полную неосведомленность, отчужденность и не включенность в тематику предлагаемого материала. На следующем этапе в исследовании приняли участие 170 человек: 100 мужчин и 70 женщин.

Первым респондентам была предложена анкета, состоящая из 14 вопросов, направленных на выявление уровня морально-нравственной рефлексии. Результаты анкетирования обрабатывались при помощи количественного контент-анализа. Процедура проведения контент-анализа заключалась в обработке текста посредством поиска единиц анализа, отражающих подтверждение присутствия признака объекта, отражающегося в определенной характеристике респондентов, значимых для нашего исследования. Категории анализа были выделены дедуктивным методом из смыслового поля вопросов. Количество категорий совпадает с количеством вопросов анкеты. Каждая категория анализа соответствует конкретному вопросу анкеты. Подкатегории анализа были выведены при помощи индуктивного метода на основе исследуемых ответов респондентов. Сначала содержательные элементы текста были выделены, затем занесены в единый список и обобщены в подкатегории. Критерием оценки наличия той или иной категории выступало присутствие в тексте таких единиц анализа, как: слово, словосочетание, предложение, суждение, высказывание, чувство, фамилия. Также учитывалась полнота ответа на вопрос. Так, закрытые ответы, не предполагающие смыслового подтверждения, рассматривались нами как отсутствие категории анализа, не содержащие эмоционально-личностного отношения к проблематике заданной вопросом. На основании проведенного 
анализа текста был составлен словарь-классификатор и кодировочная матрица контент-анализа. Процедура подсчета баллов производилась по заранее определенной методике шкалирования: за каждый вопрос анкеты респондент получал либо «+», либо «-», что предполагало наличие или отсутствие определенной категории контент-анализа в ответе респондента.

Вторым испытуемым была предложена анкета № 2, состоящая из 40 пунктов, включающих в себя морально-нравственные категории, которые респондент должен оценить по степени важности для себя от 0 до 10 баллов. Оценка баллов производилась суммированием числовых показателей по всем пунктам методики. Максимальное предполагаемое методикой количество баллов - 400, минимальное - 0. Чем больше баллов набрал респондент, тем выше для него уровень значимости морально-нравственных категорий.

Баллы, полученные по результатам двух исследований (анкета № 1 и анкета № 2), мы перевели в нормированные показатели (т. е. нормировали показатели каждого респондента к общей базе, привели их к единице). Таким образом, максимальное значение для каждого из исследований составляет единицу, а минимальное ноль. Далее мы объединили результаты по двум методикам, вычислив между ними среднее значение. Для цели суммирования исследования считаются равнозначными, т. е. весовой коэффициент каждого составляет 50 \%, что позволяет находить результат методом простого среднего.

Проранжировав результаты участников от меньшего к большему значению в соответствии с гипотезами и задачами нашей работы, мы сформировали две группы респондентов с одинаковым количеством респондентов по 60 человек, исключив среднюю часть выборки (50 человек), т. е. респондентов с промежуточными значениями.

В первую группу вошли респонденты с наименьшим количеством балов, со средним итоговым значением по результатам двух исследований от 0,31 до 0,45 (в дальнейшем группа № 1) - респонденты с низким уровнем моральнонравственной рефлексии).

Во вторую группу вошли респонденты с наибольшим количеством баллов, со средним итоговым значением от 0,70 до 0,85 (в дальнейшем группа № 2) респонденты с высоким уровнем морально-нравственной рефлексии.

\section{Результаты первого этапа экспериментального исследования}

В результате обработки анкеты № 1 нами были выявлены 14 категорий контент-анализа:

1) оценка респондентом нравственности как необходимого личностного качества современного человека;

2) сформированное семантическое поле относительно понятия «нравственность»;

3) наличие позиции относительно морально-нравственного состояния современного общества; 
4) обсуждение вопросов, касающихся морально-нравственной тематики с другими людьми;

5) личное отношение к теме причин нравственной деградации современной личности;

6) умение дать духовно-нравственную оценку личности другого человека;

7) ответственная позиция относительно своего уровня нравственного развития;

8) стремление к конкретным нравственным идеалам;

9) чтение литературы духовно-нравственной направленности;

10) любовь к классической музыке;

11) наличие в жизни конкретных нравственных поступков;

12) проявление интереса к тематике анкеты морально-нравственной направленности;

13) желание повышать уровень своей осведомленности о феномене морально-нравственного;

14) стремление к развитию уровня внутреннего морально-нравственного потенциала.

В дальнейшем описании результатов исследования по анкете № 1 мы опускаем промежуточные результаты, полученные по общей выборке (170 человек), и приводим данные по двум экспериментальным группам (по 60 человек в каждой), сформировавшихся по результатам обработки двух анкет, т. к. эта информация представляется нам наиболее интересной.

Отразим на диаграмме 1 присутствие в процентном выражении категорий контент-анализа для двух экспериментальных групп.

Таблица 1

Обобщенные результаты исследования по Анкете № 2

\begin{tabular}{|l|c|c|c|c|}
\hline \multicolumn{1}{|c|}{ Респонденты } & $\begin{array}{c}\text { Кол-во } \\
\text { человек } \\
\text { в группе }\end{array}$ & $\begin{array}{c}\text { Максим кол- } \\
\text { во баллов по } \\
\text { методике }\end{array}$ & $\begin{array}{c}\text { Набрано } \\
\text { баллов }\end{array}$ & $\begin{array}{c}\text { \% от общего } \\
\text { количества } \\
\text { возможных } \\
\text { баллов }\end{array}$ \\
\hline Общая выборка & 170 & 68000 & 43117 & $63 \%$ \\
\hline Группа № 1 & 60 & 24000 & 12130 & $50,5 \%$ \\
\hline Группа № 2 & 60 & 24000 & 18690 & $77,8 \%$ \\
\hline $\begin{array}{l}\text { Респонденты } \\
\text { со средними } \\
\text { показателями }\end{array}$ & 50 & 24000 & 12297 & $51,2 \%$ \\
\hline
\end{tabular}



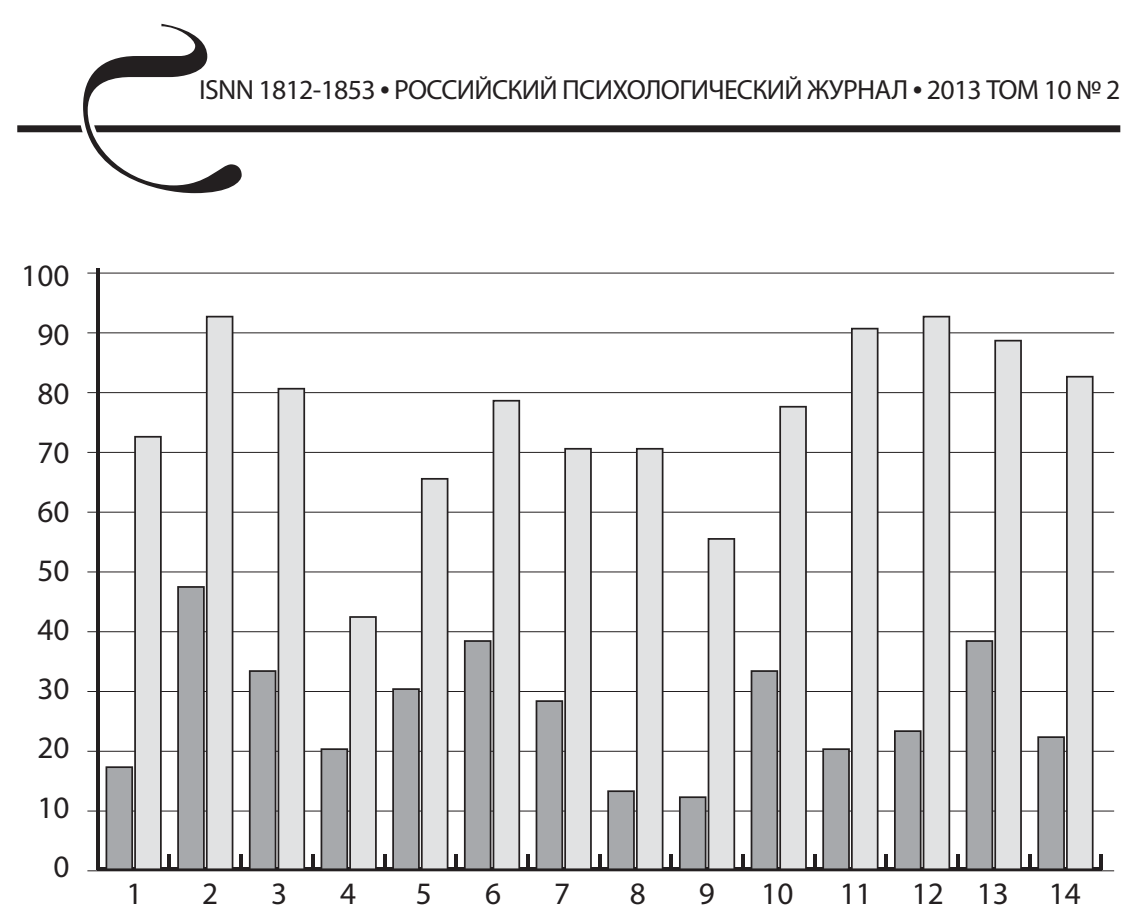

\begin{tabular}{|l|l|l|l|l|l|l|l|l|l|l|l|l|l|l|}
\hline$\square \begin{array}{c}\square \text { группа №1- низкий } \\
\text { уровень морально- } \\
\text { нравственной рефлексии }\end{array}$ & 17 & 47 & 33 & 20 & 30 & 38 & 28 & 13 & 12 & 33 & 20 & 23 & 38 & 22 \\
\hline $\begin{array}{c}\square \text { группа №2- высокий } \\
\text { уровень морально- } \\
\text { нравственной рефлексии }\end{array}$ & 72 & 92 & 80 & 42 & 65 & 78 & 70 & 70 & 55 & 77 & 90 & 92 & 88 & 82 \\
\hline
\end{tabular}

Диаграмма 1. Присутствие в процентном выражении категорий контент-анализа для двух экспериментальных групп

Результаты, полученные по анкете № 2, позволили нам выявить общий уровень значимости для респондентов морально-нравственных категорий, а также обозначить наиболее значимые для современного взрослого морально-нравственные категории. Результаты данного исследования отражены в таблице 1.

Результаты исследования по каждому из 40 морально-нравственных качеств, для отдельных групп респондентов, представлены в сводной таблице 2.

По результатам данного исследования можно констатировать факт, что как респонденты общей выборки, так и респонденты двух экспериментальных групп указали категорию «смысл жизни» как наиболее важную.

По общей выборке также получили высокие баллы такие категории, как: «внутренняя гармония» и «счастье». Эти категории оказались наиболее важны также для двух экспериментальных групп.

В группе № 1 высокие баллы получили еще 2 категории: «уважение к старшим» и «забота». 
Респонденты группы № 2 считают важным развивать морально-волевую сферу и особо выделяют такие категории, как: «уважение к людям», «духовное самосовершенствование» и «доброжелательность».

Таблица 2

Результаты исследования по каждому из 40 морально-нравственных качеств для отдельных групп респондентов

\begin{tabular}{|l|l|l|}
\hline Респонденты & $\begin{array}{l}\text { Морально-нравственные } \\
\text { категории, оцененные } \\
\text { респондентами как наиболее } \\
\text { важные }\end{array}$ & $\begin{array}{c}\text { Морально-нравственные } \\
\text { категории оцененные } \\
\text { респондентами как наименее } \\
\text { важные }\end{array}$ \\
\hline $\begin{array}{l}\text { Общая } \\
\text { выборка }\end{array}$ & $\begin{array}{l}\text { Смысл жизни, внутренняя гар- } \\
\text { мония, счастье. }\end{array}$ & $\begin{array}{l}\text { Коллективизм, умеренность, } \\
\text { патриотизм, альтруизм, долг, } \\
\text { равенство людей. }\end{array}$ \\
\hline Группа № 1 & $\begin{array}{l}\text { Смысл жизни, счастье, вну- } \\
\text { тренняя гармония, уважение } \\
\text { К старшим, забота. }\end{array}$ & $\begin{array}{l}\text { Всепрощение, патриотизм, } \\
\text { совесть. }\end{array}$ \\
\hline Группа № 2 & $\begin{array}{l}\text { Внутренняя гармония, } \\
\text { смысл жизни, развитие } \\
\text { морально-волевой сферы, } \\
\text { уважение к людям, духовное } \\
\text { самосовершенствование, } \\
\text { доброжелательность. }\end{array}$ & $\begin{array}{l}\text { Коллективизм, равенство } \\
\text { людей. }\end{array}$ \\
\hline
\end{tabular}

Участники общей выборки и группы № 2 поставили минимальное количество баллов таким категориям, как: «коллективизм» и «равенство людей».

По общей выборке низкие баллы также получили такие категории, как: «умеренность», «патриотизм», «альтруизм» и «долг».

Респонденты группы № 1 считают неважными для себя такие категории, как: «всепрощение», «патриотизм» и «совесть».

Таким образом, на первомэтапе экспериментального исследования нами были разработаны две анкеты для изучения уровня морально-нравственной рефлексии респондентов. Полученные результаты позволили разделить респондентов на 2 экспериментальные группы с низкой (группа № 1) и высокой (группа № 2) степенью морально-нравственной рефлексии.

Наш научный интерес обусловлен исследованием взаимосвязи способности личности к морально-нравственной рефлексии, ее стремлением к личностному развитию, а также уровнем развития ее смысловой сферы, поэтому следующим этапом нашего экспериментального исследования мы планируем сравнение двух экспериментальных групп по следующим параметрам: актуальность потребности в самореализации (методика актуальности основных 
потребностей «Парные сравнения» в модификации И.А. Акиндиновой); степень реализации потребности в саморазвитии («Диагностика реализации потребности в саморазвитии»); устойчивость желательных ценностных отношений к жизни, к людям, к себе (тест «Пословицы» С.М. Петровой); смыложизненные ориентации: осмысленность, насыщенность жизни, удовлетворенность самореализацией, направленность локуса ответственности («Тест смысложизненных ориентаций» Д.А. Леонтьева); общий уровень рефлексивности («Определение уровня развития рефлексивности» А.В. Карпова).

\section{Литература}

1. Абакумова И.В., Кагермазова Л.Ц., Савин В.А. Диалог культур как смыслотехнология формирования установок толерантного сознания и поведения студентов вуза // Российский психологический журнал. - 2013. - Т. 10. - № 1. - С. 46-59.

2. Алмаев Н.А. Применение контент-анализа в исследованиях личности: методические вопросы. - М.: Изд-во «Институт психологии РАН», 2012. - 167 с.

3. Асмолов А.Г. Психология личности: культурно-историческое понимание развития человека: учебник. 4-е изд. - М.: Смысл; Издательский центр «Академия», 2010. - 448 с.

4. Братченко С.Л., Миронова М.Р. Личностный рост и его критерии // Психологические проблемы самореализации личности. - СПб., 1997. - С. 38-46.

5. Валиаментов Х.Х. Духовно-нравственное развитие личности в учебнособытийной деятельности: дисс.... канд. псих. Наук. - Казань, 2003.

6. Галажинский Э.В. Поиск методологических оснований изучения психологических детерминант самореализации личности. - URL: http://psy.tsu.ru/ data/pdf/3_07.pdf (дата посещения 20.05.2013).

7. Гостев А.А., Борисова Н.В. Психологические идеи в творческом наследии И.А. Ильина: на путях создания психологии духовно-нравственной сферы человеческого бытия. - М.: Изд-во «Институт психологии РАН», 2012. -288 с.

8. Клочко В.Е., Галажинский Э.В. Самореализация личности: системный взгляд / под ред. Г.В. Залевского. - Томск: Издательство Томского университета, 1999.

9. Леонтьев Д.А. Самореализация и сущностные силы человека // Психология с человеческим лицом: гуманистическая перспектива в постсоветской психологии / под ред. Д.А. Леонтьева, В.Г. Щур. - М.: Смысл, 1997. - 335 с.

10. Леонтьев Д.А. Духовность, саморегуляция и ценности. - URL: http://www. institut.smysl.ru/article/spirit.php (дата посещения 20.05.2013).

11. Леонтьев Д.А., Иванченко Г.В. Комплексная гуманитарная экспертиза: методология и смысл. - М.: Смысл, 2008. - 133 с. 
12. Maddi S. Creating Meaning Through Making Decisions // The Human Search for Meaning / ed.by P.T.P.Wong, P.S.Fry. Mahwah: Lawrence Erlbaum, 1998, p. 1-15.

13. May R. Psychology and the Human Dilemma. Princeton: Van Nostrand, 1967. p. 168-181.

14. Тарасьян Н.А. Особенности духовности и самосознания современного российского юношества: дис.... д-ра психол. наук. - Ставрополь, 2012.

15. Штумпф С.П. Духовность как социокультурный феномен: аксиологическая направленность и перспективы развития: дис.... канд. психол. наук. - Иркутск, 2007. 